\title{
Instruments of subject-to-subject interaction in blended learning: visual didactic regulators
}

\author{
Rail Asadullin ${ }^{1 *}$, Valeriy Shteinberg ${ }^{2}$, Nataliya $\mathrm{Manko}^{3}$, Lyutsiya Vakhidova ${ }^{4}$, and \\ Nadezhda Sytina $^{3}$ \\ ${ }^{1}$ Bashkir State Pedagogical University named after M.Akmulla, Committee on Education, Culture, \\ Youth Policy and Sports of the State Assembly - Kurultai of the Republic of Bashkortostan, \\ Research Institute for Education Development Strategy, Ufa, Russia \\ ${ }^{2}$ Bashkir State Pedagogical University named after M.Akmulla, Research Laboratory for Modeling \\ Visual Regulators of Logical and Semantic Type, Research Institute for Education Development \\ Strategy, Ufa, Russia \\ ${ }^{3}$ Bashkir State Pedagogical University named after M.Akmulla, Department of Pedagogy, Ufa, Russia \\ ${ }^{4}$ Bashkir State Pedagogical University named after M.Akmulla, Department of Pedagogy and \\ Psychology of Professional Education, Ufa, Russia
}

\begin{abstract}
Research background implies changing the mechanisms of subject-to-subject interaction, control, and feedback when transiting to distance and mixed learning; one of the areas of difficulties that arise during such transition is the search for a way to partially compensate for difficulties using new visual didactic tools. Research goal includes searching for new visual didactic tools based on cognitive visualization of knowledge that support and guide educational cognitive activity, interaction, and feedback in the context of distance and classroom learning. The authors use a method for analyzing the development of visual tools based on the criterion of implementing cognitive principles of knowledge representation; a method for logical and semantic modeling of knowledge using universal educational actions; a method for constructing visual tools based on graphical visualization of logical and semantic modeling of knowledge presented in natural language (the language of study). New visual didactic tools developed by the authors, and implementing illustrative and regulatory functions, are proposed to be called "visual didactic regulators of logical and semantic type" and used for subject-tosubject interaction in distance learning. The basis of such tools is also the logical and semantic models proposed by the authors, whose usefulness has been confirmed by long-term testing in the classroom training; currently, regulators are used in distance learning as an experiment.
\end{abstract}

Keywords: classroom and distance learning, subject-to-subject interaction, visual didactic regulators, logical and semantic modeling.

\footnotetext{
*Corresponding author: rail 53@mail.ru
} 


\section{Introduction}

\subsection{Research background}

When transiting to distance learning, along with organizational, informational, software, and hardware-related difficulties, the consequences of the loss of well-thought-out and well-developed methods of educational work that are effective in the in-class learning were revealed. The educational activity is reduced to the assimilation of disciplinary knowledge. At that, the subject position of the student becomes beyond the framework of pedagogical management of the educational process, and team discussion of the object under study is curtailed. In this context, the role of didactic tools that reflect the structure of the content of educational material and/or educational activities, support and guide educational cognitive activity, that is, have regulatory properties, increases. It can be assumed that such tools will be useful in the interaction of teachers and students in the new environment, and thus their research and development is appropriate.

\subsection{Review of the theoretical base of the research}

Scientists' discussions of multidimensional problems of distance learning have intensified in recent years. Thus, A. Baldiš justified the coordination of research in pedagogy with changes in the digital environment and social behavior of its participants [1]. Criticism of decisions made in distance education technology is necessary according to B. Williamson, R. Eynon, and J. Potter [2]. A.I. Oliveira, R.F. Behnagh, L.Ni, A.A. Mohsinah, K.J. Burgess, and L. Guo recommend mastering technological tools as tools for cognition and constructing reality [3]. S. Schwartz points out the inadmissibility of overloading teachers [4].

The problem of subject-to-subject interaction is being also investigated, for example by M. Alhih, E. Ossiannilsson, and M. Berigel, who identified an increased need for educational process subjects in various types of interaction, namely student-to-student, student-to-teacher, and others [5]; S. Telhaj associated the increase in student performance with the presence of successful peers [6]. C. Roddy, D.L. Amiet, J. Chung, C. Holt, L. Shaw, S. McKenzie, F. Garivaldis, J.M. Lodge, and M.E. Mundy studied the success factors of intensive online learning at additional requirements for students and teachers [7]. W.N. Tasnim, W. Hussin, J. Harun, and N. A. Shukor justified the need to encourage active students' interaction [8]. It can be seen that the subject-to-subject interaction factor will increasingly determine the effectiveness of resources and the distance learning system in general as technical issues are resolved (the convenience of digital platforms, the speed of network communication, etc.).

Similar problems of distance learning are being studied by Russian scientists, and one should expect solutions that will become suitable for use in practice. It should be noted that the current task of forming an adequate materialized mental image of the studied knowledge in the learning process was considered earlier. For example, R.M. Asadullin demonstrated on the example of Waldorf pedagogy that the picture of pedagogical reality represented a holistic multidimensional image [9]; T.A. Tyutyunnikova associated holographic projections method with the implementation of vitagenic education and transformation of subject-to-object relations to subject-to-subject relations [10]; multidimensionality as an objective feature of reality was implemented in didactics of V.E. Shteinberg based on cognitive knowledge visualization [11], which, as was shown by N.N. Manko, developed the principle of visual clarity in teaching and transformed illustrative learning tool into means of supporting cognition and development of thinking [12]. The latest results are included in the global visualization trend, which is actively developed by 
T. Buzan [13] and J.D. Novak [14], as well as by other scientists who implement and develop their ideas when solving various applied problems [15-17]. Currently, concept maps, used widely in teaching and research, when analyzing problems and generating ideas, are contributing to the development of visual literacy of users.

However, many visual tools have not been sufficiently studied as semiotics objects and from the standpoint of universality; they have not been sufficiently tested at various levels of education, even though the activity regulators were a mature and researched phenomenon used in the form of meanings, values, goals, and rules in various industries [18-20]. Representational tools as didactic regulators, especially visual ones, have not been studied enough for educational activities, as proven by searching in the electronic scientific library Elibrary.ru and the Internet.

\subsection{Justification of the research novelty}

The review of literature sources shows that the traditional educational process aimed at the subject-based development of students in the distance learning system significantly loses its pedagogical potential. This results in the necessity to search for tools, including visual ones that promote subject-to-subject interaction, independent learning activities of students, and the development of self-organization, self-management, and self-control skills.

\subsection{The research hypothesis}

The research hypothesis is that visual tools used in distance learning technologies along with illustrative functions should perform regulatory functions; be designed using the knowledge modeling method and universal learning actions; have a universal and convenient visual form. Tools, such as didactic visual regulators should become an important element of distance and classroom learning technologies, while their application will be appropriate at various levels of the education system.

\subsection{The research goal}

The research goal is to analyze the development of visual tools and determine the direction of their improvement as a means of cognitive visualization of knowledge presented in the language of study, having informational and regulatory properties, that is, supporting and directing educational cognitive activity, as well as interaction and feedback in the context of distance and classroom learning. Such tools complement well-known visual conceptual and graphical solutions, such as mental maps, frames, structural and logical schemes, etc.

\subsection{Research objectives}

In line with the set goal, the following objectives should be solved: to clarify the development direction of visual tools as means of cognitive visualization skills; to identify the factors of supplementing information properties by the regulatory factors, and determine the factors of the transformation of the representational attribute into the visual attribute; as well as to clarify features of the construction of the new teaching methods and applied aspects in the context of digitalization of education. 


\section{Methods}

The authors used the following methods: a method for analyzing the development of visual tools based on the criterion of implementing cognitive principles of knowledge representation, and logical and semantic modeling of knowledge using universal educational actions; a method for constructing didactic regulators based on combining the content component, i.e. the result of logical and semantic modeling ${ }^{\dagger}$ of knowledge and the graphic component.

\section{Results}

The analysis of the visual didactic tools ${ }^{\ddagger}$ development has allowed distinguishing four integrated stages:

a) using images and concepts in the teaching process (J.A. Comenius, 1633);

b) creating semantic networks (C. Peirce, 1909), developing a method of logical and semantic modeling of text to be processed by computer (M.M. Subbotin, 1956);

c) creating frames (L.M. Marvin, 1974); inventing memory maps (T. Buzan, 1968);

d) developing logical and semantic models and regulators on their basis (V.E. Shteinberg, N.N. Manko, L.V. Vakhidova, 1988-2020).

Using development means allows improving structuring, namely, introducing conditional images and symbols of elements and links; using cognitive principles of knowledge representation, namely, structuring content, linking structure parts, curtailing designations of parts and reducing them to keywords; applying visualization of logical and semantic modeling of knowledge using coordinate-matrix graphics; using universal training actions, such as splitting topics into parts, ranking parts, highlighting nodal content elements, ranking elements and placing them on coordinates, identifying links between nodal elements, and curtailing coordinate designations, nodes, and links. Comparing visual tools by the criterion of applying logical and semantic modeling operations using universal training actions has shown that the above operations were less implemented when building structural diagrams and reference signals; they were implemented to a greater extent when building semantic networks, frames, graphs, and mental maps; and to a full extent - when building logical and semantic models based on coordinate-matrix graphics. Combining the structured content of the displayed knowledge and the graphical coordinate-matrix basis allowed developing visual logical and semantic models and further, on their basis, visual didactic regulators of the logical and semantic type (Fig. 1).

The characteristics of logical and semantic models and graphic archetypes were studied. At that, models were studied as a semiotics object [21]. Visual concept-regulators of logical and semantic type were designed for solving project tasks. Their main feature is the matrix of professional growth of a teacher (or any other specialist), placed in the fourth quadrant (Fig. 2).

\footnotetext{
$\dagger$ Logical and semantic modeling of knowledge is a method of modeling knowledge by decomposing the object or process under consideration, whose description is presented in natural language (the language of study), using a package of universal learning actions (the language of study)

$\$$ Visual didactic regulators of the logical and semantic type are a visually perceived image of a conceptual and graphic means of visualization, designed by the method of logical and semantic modeling of knowledge with the placement of modeling results, namely, nodal elements of content and their relationships, denoted by keywords, in a reference-nodal coordinate-matrix system
} 


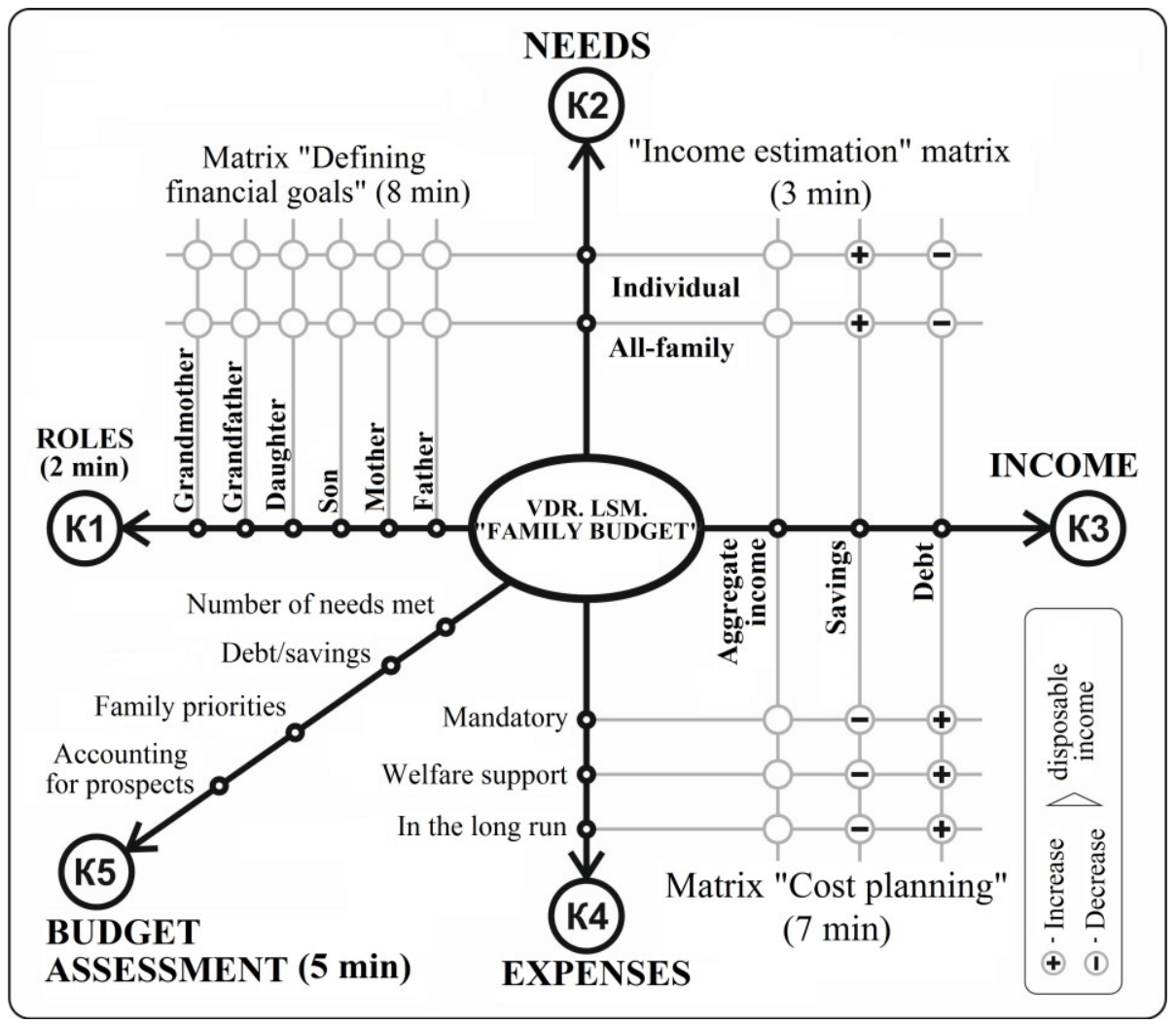

Fig. 1. Visual didactic regulator: "Family budget" business game.

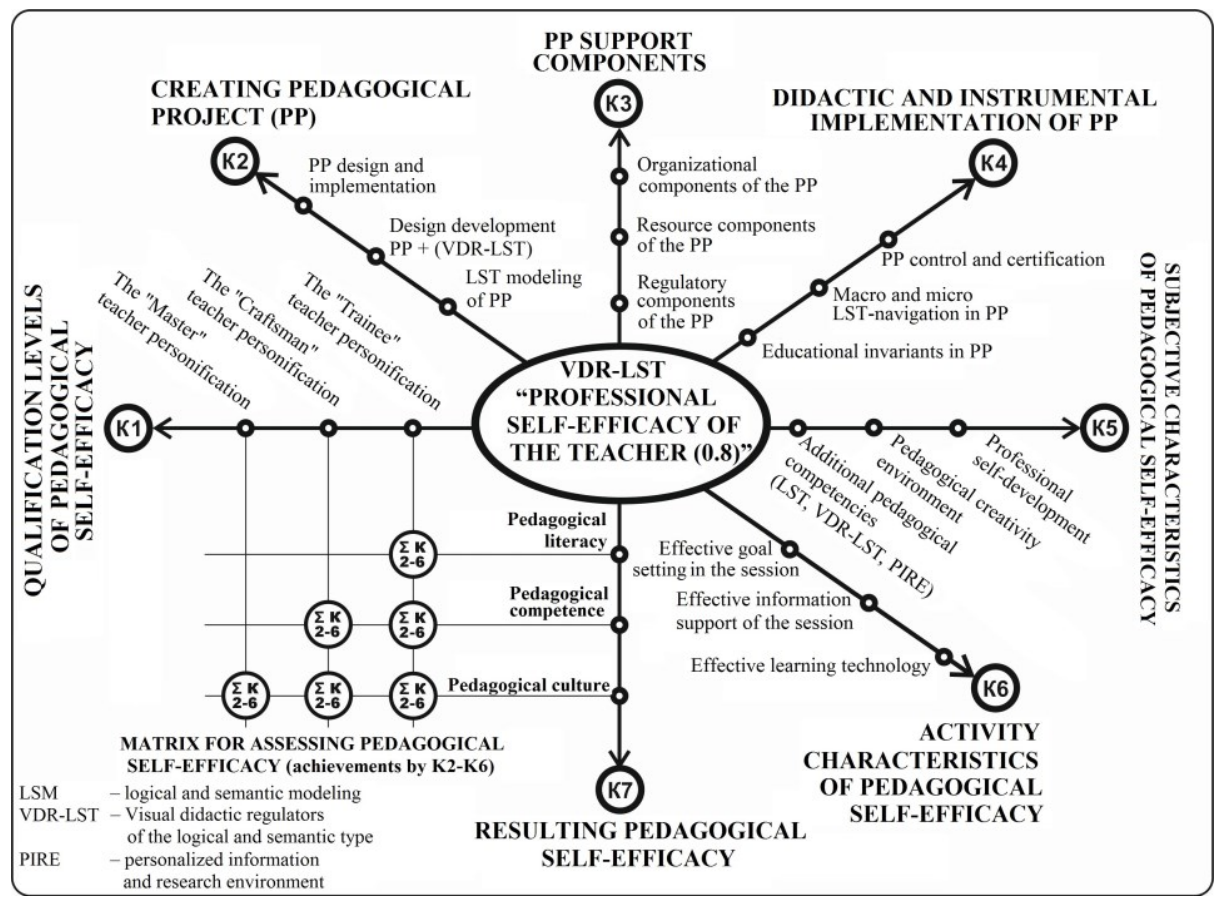

Fig. 2. Visual concept-regulator "Professional self-efficacy of a teacher (08)". 
Such regulators are used when creating computer programs with an interactive interface designed to form the professional self-efficacy of the teacher and use it in the system of full-time, corporate, and individual training [22].

\section{Discussion}

The use of visual didactic regulators of the logical and semantic type in in-class learning, as well as at remote classes with students and undergraduates of the pedagogical profile contributes to the interaction of the teacher and students, which confirmed the formulated hypothesis and allowed continuing experimental work. The similar regulators on the sending and receiving sides of the distance learning system contribute to the synchronization of subject-to-subject interaction and communication. Such regulators were used as navigators in the content of learning material during the remote implementation of case programs in students' education. They contributed to the improvement of subject-tosubject interaction and receiving feedback [23]. To form the teacher's readiness to use new didactic tools, the training program, named "Visual didactic regulators of the logical and semantic type" (VDR-LST) was developed [24].

The demand for new didactic tools by teachers is illustrated by searching the Internet for the tags like "visual didactic regulators" and "logical and semantic models"; as well as a selection of educational and methodological developments posted on the cloud service.

\section{Conclusion}

The results of the study have shown that representational conceptual and graphical tools are developing toward improving the basic information and regulatory properties, whose improvement is achieved using cognitive principles of knowledge representation and logical and semantic modeling of knowledge using universal educational actions. Regulators based on the integration of logical and semantic modeling of knowledge and coordinate-matrix graphics complement the known representational tools by using universal educational actions, visual convenience, and greater versatility in their construction.

The developed regulators should be used in distance and classroom learning technologies to activate subject-to-subject interaction, as a tool for the educational cognitive activity of the student with increased requirements for self-organization and selfcontrol, as a means for communication and navigation in the content of learning material and educational activities, as well as an interactive interface when creating computer programs.

\section{Acknowledgments}

The article was prepared in the framework of the grant of the Bashkir State Pedagogical University named after M. Akmulla (BSPU) "Theory and technology of modeling of logical and semantic regulators for educational projects" (Order No. 207/0 of 04.06.2020).

\section{References}

1. A. Baldiňš, Procedia - Social and Behavioral Sciences, 231, 251-255 (2016). https://doi.org/10.1016/j.sbspro.2016.09.099

2. B. Williamson, R. Eynon, J. Potter, Learning, Media and Technology, 45(2), 107-114 (2020). https://doi.org/10.1080/17439884.2020.1761641 
3. A. Oliveira, R.F. Behnagh, L. Ni, A.A. Mohsinah, K.J. Burgess, L. Guo, Human behavior and emerging technologies, 1(2), 149-160 (2019). https://doi.org/10.1002/hbe2.141

4. S. Schwartz, Education Week (2020). Accessed on: December 29, 2020. [Online]. Available: https://www.edweek.org/ew/articles/2020/08/06/classroom-routines-haveto-change-heres-what.html

5. M. Alhih, E. Ossiannilsson, M. Berigel, EURASIA Journal of Mathematics Science and Technology Education, 13(6), 2733-2748 (2017). https://doi.org/10.12973/eurasia.2017.01250a

6. S. Telhaj, IZA World of Labor, 440 (2018). https://doi.org/10.15185/izawol.440

7. C. Roddy, D.L. Amiet, J. Chung, C. Holt, L. Shaw, S. McKenzie, F. Garivaldis, J.M. Lodge, M.E. Mundy, Front. Educ. 2, 59 (2017). https://doi.org/10.3389/feduc.2017.00059

8. W.N. Tasnim, W. Hussin, J. Harun, N.A. Shukor, Universal Journal of Educational Research, 7(9A), 125-134 (2019). https://doi.org/10.13189/ujer.2019.071615

9. R.M. Asadullin, V labirintakh pedagogiki. Razmyshleniya o val'dorfskoy shkole [In the labyrinths of pedagogy. Reflections on the Waldorf School] (Dom pechati, Kazan, 1997)

10. T.A. Tyutyunnikova, Metod golograficheskih proektsiy [The method of holographic projections], in New Word in Science: Development Prospects: Materials of the VII International Scientific and Practical Conference, Center of Scientific Cooperation Interactive Plus, 15 January 2016, Cheboksary, Russia (2016)

11. V.E. Shteinberg, Obrazovaniye i nauka, 4, 3-6 (2001)

12. N.N. Manko, Izvestia of Altai State University. Series: Pedagogy and Psychology, 2 , 22-28 (2009)

13. K. Gjorgievska, A Big Special 'Thank you' to the Inventor of Mind Maps - Tony Buzan (2019). Accessed on: October 14, 2020. [Online]. Available:

https://www.imindq.com/blog/a-big-special-thank-you-to-the-inventor-of-mind-mapstony-buzan

14. Concept Mapping and the Theory Behind. Internet resource (2020). Accessed on: October 14, 2020. [Online]. Available: https://www.imindq.com/uses/concept-mapping

15. S. Mazzucca, E.P. Betit, J. Bunting, R. Tabak, CPWR R2P Concept Mapping Report (2019). Accessed on: October 14, 2020. [Online]. Available:

https:/www.cpwr.com/wp-content/uploads/publications/RR2019-concept-mapping.pdf

16. A. Bauman, College Teaching, 66(4), 213-221 (2018). https://doi.org/10.1080/87567555.2018.1501656

17. McGraw Hill, PreK-12 Research Portal: Visual Literacy in a Digital World: A Guide for Educators Featuring a White Paper from Shannon Flaum (2018). Accessed on: December 15, 2020. [Online]. Available: https://medium.com/inspired-ideas-prek12/visual-literacy-in-a-digital-world-a-guide-for-educators-3204ca802804

18. Z.N. Khabibullina, Historical, Philosophical, Political and Law Sciences, Culturology and Study of Art. Issues of Theory and Practice, 1(63), 184-186 (2016)

19. P.V. Rybalkina, NOMOTHETIKA. Filosofiya. Sotsiologiya. Pravo, 3(252), 158-161 (2017)

20. B.G. Yudin, V fokuse issledovaniya - chelovek: eticheskiye regulyativy nauchnogo poznaniya [The focus of the research is on humans: ethical regulations of scientific 
knowledge], in Philosophiya nauki, 11, 224-242 (2005). Accessed on: December 15, 2020. [Online]. Available: https://iphras.ru/uplfile/root/biblio/ps/ps11/14.pdf

21. V.E. Shteinberg, N.N. Manko, Obrazovaniye I nauka, 19(9), 9-31 (2017). https://doi.org/10.17853/1994-5639-2017-9-9-31

22. L.V. Vakhidova, V.E. Shteinberg, Ye.V. Tkachenko, R.S. Khakimzhanov, N.N. Manko, E.M. Gabitova, E.M. Galiakhmetova, O.A. Gorlitsyna, Electronic program "Professional self-efficacy of a teacher". Certificate RU 2018614157 (2018)

23. V.E. Shteinberg, N.S. Sytina, N.N. Manko, Tekhnologiya Kognitivnoy Navigatsii V Keys-Programmakh Podgotovki Spetsialista [Technology Cognitive Navigation In The Case, The Programmes Of Specialist Training For Students And Graduate Students Of Pedagogical Universities] (Narodnoye obrazovaniye, Moscow, 2017)

24. V.E. Shteinberg, N.N. Manko, L.V. Vakhidova, Educational program "Visual didactic regulators of the logical and semantic type (VDR-LST)". Certificate RU 2020614674 (2020) 